\title{
Application of RFID in Agricultural Product Industry
}

\author{
Min Zhang ${ }^{1, a}$, Yu-Hua Wu ${ }^{1, b}$, Ting Yang ${ }^{1, c}$, Shi-Jun $\mathrm{Li}^{\mathrm{d}, *}$ \\ ${ }^{1}$ Jilin Agricultural University, Changchun 130118, Jilin, China

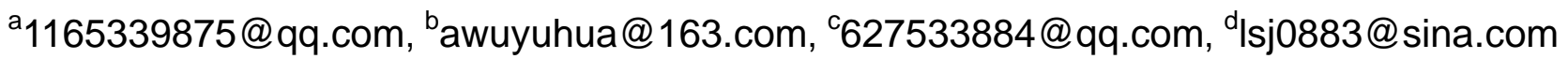 \\ *Shi-Jun LI
}

Key words: RFID, agricultural product, application, prospect

\begin{abstract}
RFID (Radio frequency identification) is an emerging technology that can usher enormous opportunities in agricultural product industry. This paper presents a review of applications of RFID in traceability, cold chain monitoring, livestock management, supply chain management. It also discusses the basics of RFID devices and the difficulties in the current application process. Finally, we analyzed the RFID application prospect in the future.
\end{abstract}

\section{Introduction}

The agricultural industry due to its special nuture, whitch is susceptible to many factors, such as the weather changes, the spread of the disease and the product decay problem happened in transit etc. Therefore, the real-time and efficient access to a wide range of agricultural information is essential to the management of agricultural modernization.

Radio Frequency Identification(RFID) technology as a rapid, real-time, accurate collection and processing of high-tech and the basis of information standardization, has been acknowledged in the world as one of the ten important technologies in the 21st century, in the production, retail, logistics, transportation and other industries have broad application prospects. Currently, the technology in the agricultural industry has been very common. In terms of tracing agricultural products: Yang Yong et al using RFID technology, Microsoft Visual Studio 2010 development tools and Microsoft SQL Server 2008 database management system developed the organic vegetable traceability management system with agricultural enterprises' own characteristics[1]. Sun Xudong et al Application of RFID technology, two-dimensional code technology, asp.net component technology and other multi-disciplinary techniques, for each participating object traceability chain have carried out a unique code, so as to ensure traceability chain on each participating object coding with traceability and integrity[2]. In cold chain monitoring: Wang Tingman et al in Tilapia as an example, based on RFID technology, using Visual Studio2005 and SQL server2005, combined with the coding technology developed a cold chain logistics temperature monitoring system[3]. In livestock management: Geng Li wei et al through the use of RFID technology and single-chip and PC communication technology for remote identification and timely realization of each cow monitoring and management[4]. In the field of agricultural products supply chain management: Lu Lin et al using RFID tags as information carriers to transmit information, via the Internet, networking and circulation of agricultural products information network "triple play" construction and integration of analysis, proposed a kind of agricultural products based on the supply Chain architecture, thus ensuring the quality and safety of the agricultural products[5].

\section{Basics of RFID}

Generally, The RFID system consists of three parts: electronic tags, readers and data management system. Among them, the electronic tag stores information about the object to be recognized, and 
each tag has a unique electronic code, attached to the object identifies the target object; reader performs wireless communication through the antenna and the electronic tag can be achieved on the tag identification code and memory data read or write operation; data management system is mainly to complete the data information storage and management, and control and management of the label [6].

When the RFID system works, RFID reader via the antenna continued to send out a signal of a certain frequency, when the RFID tag into the magnetic field induced current obtained with the energy sends out product information (Passive Tag), or take the initiative to send a signal (active tag) frequency; then the reader to read and decode the information, the data is transferred to a data management system relating to data processing operations.

\section{Problems encountered in the application}

The application of RFID technology in the agricultural industry has a broad application prospect. However, the practical application is still facing many problems. for example: standardization, cost, privacy and security issues and environmental issues, etc.

\section{Standardization}

The main problems that restrict the development of radio frequency identification system is incompatible standards. Existing RIFD systems may use different frequencies, different countries may put a different radio band allocated to different uses. Major manufacturers to provide radio frequency identification system is a dedicated system, leading to different applications and different industries with a frequency and protocol standards from different vendors, this confusion and separatist situation has hampered the growth of the entire RFID industry. Many European organizations are working to solve this problem, and has achieved some achievements. Standardization will stimulate substantial radio frequency identification technology development and widely application.

\section{Cost}

The cost issue is an important limiting factor in the implementation of RFID technology in various industries. RFID system in the actual application process requires a lot of cost, these costs include not only the use of tags and readers and other hardware devices, but also includes the management system software upgrades and follow-up system maintenance costs. However, the agricultural industry is a relatively low-profit industry, large-scale adoption of RFID systems in the agricultural industry need to invest too much cost, so we must reduce the costs. With the development of science and technology, it is expected that advances in semiconductor manufacturing technology will reduce the cost of key parts of the system, which will significantly reduce the overall implementation cost of the RFID system to a certain degree.

\section{Privacy and security issues}

Privacy and security is a major challenge for RFID technology in the agricultural industry application. Because of the RFID system relies on transmitting radio frequency signals to communicate with each other, the data communicated between the tag and the reader is exposed to the air, and is easily attacked by hackers, thus threatening the privacy and security of individuals or businesses. At present, researchers are working hard to construct a reliable security mechanism for RFID system. 


\section{Environmental issues}

RFID system in the agricultural industry, inevitably affected by environmental factors such as the case of dust, moisture, extreme temperatures, mechanical vibration, peripheral equipment, metal interference, electromagnetic interference etc; In addition, RFID reader or antenna position orientation, location and tag pasting paste methods will also have an impact on the reliability of the RFID system, causing the system to the low rate of literacy, the high error rate and so on. Therefore, in view of the RFID in agricultural products on different application forms, how most dramatically reduce the RFID system in the process of practical application is affected by environment and damage is still needs to be continuously research.

\section{Conclusion and future trends}

Along with the progress of science and technology, modern agriculture has been from the traditional agriculture gradually to the development of modern agriculture. China is a large agricultural country, the application of RFID technology in the field of agricultural products industry, will to a certain extent, improve China's agricultural products quality supervision ability, agricultural logistics management capabilities, the traceability of agricultural products and market competitiveness. Although in the field of agriculture, through the use of RFID technology has made some progress, but its technical potential has not yet been fully utilized.

The combination of RFID technology and related hardware and software can be used to achieve the real-time monitoring of agricultural products, environmental remote sensing, tracking and tracing; combined with different types of sensors can be used to collect the temperature, humidity, $\mathrm{PH}$, information environment parameters such as gas concentration; combined with the Internet, by increasing the transparency of information of agricultural products that can increase the added value of agricultural products, brand management and logistics management efficiency. In addition, the RFID technology and artificial intelligence and sensor combination, can be used for the condition based decision. Currently, researchers through the use of artificial intelligence, decision support tools and a variety of sensors, to develop low-cost, longer life of the RFID system. The potential benefits of RFID is very great, by combining RFID technology with other technologies, many new applications will emerge in the near future.

\section{Acknowledgments}

The authors wish to express their gratitude to the projects:Application of RFID in Agricultural Product Industry from Education Department of Jilin Province, Jilin Province Economic Structural Adjustment Leading Fund Special Project (No. 2014Y108) and Changchun City Science and Technology Plan Project (No. 14nk029), Jilin Province Science and Technology Development Program Funded Project (No. 20160623016TC), Education Department of Jilin Province's 12th Five-Year Science and Technology Research Project (2015175), for their generous support of this work. At the same time, the other authors also thank the corresponding author, Shijun LI, for his assistance in submitting this paper.

\section{References}

[1]YANG Yong,ZHAO Xiuping.Organic vegetable traceability management system based on RFID Technology[J].China Printing and Packaging Study,2014, 6 (2) :60-65,in Chinese. 
[2]SUN Xudong,ZHANG Hailiang,OYANG Aiguo,LIU Yande.Implementation method of Citrus Quality and safety traceability information system[J].Agricultural Mechanization Research,2009,12:162-168.in Chinese.

[3]WANG Tingman,ZHANG Xiaoshuan,CHEN Wei,FU Zetian,PENG Chaohui.Tilapia cold chain logistics temperature monitoring system based on radio frequency identification technology[J].Agricultural Engineering,2011,9:141-146,in Chinese.

[4]GENG Liwei,QIAN Dongping,ZHAO Chunhui.Based on radio frequency technology cow identification system[J].Agricultural Engineering,2009,25（5）: 137-141,in Chinese.

[5]LU Lin,LIU Fengshan.Management of the supply chain of agricultural products based on Internet of Things[J].Modernizing Agriculture,2012,7:57-60,in Chinese.

[6]LANG Weimin.Radio frequency identification (RFID) technology principle and application[M].Beijing:Machinery Industry Press,2006:58, in Chinese. 